\title{
Influence of Compatibility on Adoption of Hiv/Aids Preventive Measures in Maiduguri Metropolis: A Social Marketing Perspective
}

\author{
YakakaGamama, Bintu Mustapha, $\mathrm{PhD}$
}

\begin{abstract}
The main goal of social marketing is behavioural impact and it can be applied to a variety of social problems, but behaviour change is complex. The study examined the influence of compatibilitywith culture on adoption of HIV/AIDS preventive measures in Maiduguri metropolis, specifically, the study assessed the level of awareness on HIV/AIDS; and examined the peoples' protective behaviours. Primary source of data was utilised, structured questionnaires were administered on 300 respondents; however, 283 questionnaires were valid. Multistage sampling technique was employed using stratified sampling and convenience sampling techniques to select the respondents. Secondary data were sourced through existing literature. Descriptive statistics and simple linear regression analysis were used to analyse the data. The major finding of the study revealed that prevention measures that are not compatible with culture significantly influence adoption of HIV/AIDS prevention methods. The study recommends "Cultural social marketing" should be used where community leaders and communal elders are recognised and persuaded to promote cultural practices which can prevent HIV infection rather than those practices that are barriers to its prevention.
\end{abstract}

Key Words: Social Marketing, Compatibility, Adoption, Prevention Methods, HIV/AIDS

\section{Introduction}

Marketing is not restricted to exchange of physical goods but extends to the domain of services (Kotler and Levy, 1967), individual and all organisational activities (Agbonifoh, Ogwo, Nnolim and Nkamnebe, 2007). Commercial marketing utilises the exchange concept as an element of behaviour theory, the theory states that, people are more likely to take an action when they perceive a lesser cost-benefit ratio to acting than not acting. Social marketing on the other hand, works on the premise that, in a similar manner to purchasing goods and services people weigh up the costs and benefits of engaging in all sorts of social. Social marketing in this respect aims to persuade consumers that there is more to gain than loose by adopting a precautionary behaviour (Bourne, 2011).

Social marketing is perhaps the most popular framework for designing health behaviour change campaigns through the use of commercial marketing approaches (Cugelman, 2012). Effective social marketing interventions should bring about positive social behaviour change in a target population. Social marketing has become increasingly popular among donor agencies and governments as a way of addressing serious social issues. Research shows that average social marketing campaigns can influence about 5\% of a population's behaviour (Cugelman, 2012). This 5\% impact is a ballpark figure that varies from population to population, and from behaviour to behaviour. Although 5\% may seem small, at the population level, small shifts in public behaviour can translate into large impacts.

In trying to enhance behaviour change, factors that affect consumer's acceptance of innovations have to be considered, such factors are: characteristics of the consumer and perceived characteristics of the innovation. For a good, service or idea to be adopted, consumers go through a series of stages from learning about the new product or idea (awareness) to trying it and deciding whether to adopt it or reject it. Characteristics of the consumer such as; demographic (age, gender and level of educational), psychographic, perceived characteristics of the innovation feature such as; compatibility, perceived risks, communicability and complexity affect behaviour change. Compatibilitywith an individual's values, beliefs, experiences and needs is a factor for potential adoption. A HIV prevention strategy that is not congruent with the culture, belief, experience, and needs of a consumer would have a lower likelihood of being adopted. In the context of this study, compatibility with culture will be examined.

HIV/AIDS prevention methods are innovations to consumers who have not adopted these strategies. People may be aware of the strategies but have not done anything yet. It is the goal of social marketing to move consumers from awareness to desire and action.

Despite the efforts by donor agencies and the government, there has remained a low adoption rate by people. The rapid spread of the virus could be attributed to the low adoption of prevention strategies. Social marketing may have created awareness for the strategies but the knowledge has not brought about significant 
influence on adoption rate. Are people unable to adopt due to other reasons? In terms of behavioural change, do people lack the motivation to implement knowledge into sustained behaviour change?

\section{Literature Review}

Kotler and Lee (2008)define social marketing as a process that applies marketing principles and techniques to create, communicate, and deliver value in order to influence target audience behaviours that benefit society.Social marketing requires a clear understanding of competing behaviours, socio-economic, political and cultural conditions to develop strategies compatible with existing socio-economic and cultural values of the population where the strategies are applied (Hussain and Shaikh, 2005).

Social marketing seeks to influence social behaviours not to benefit the marketer, but to benefit the target audience and general society. Studies have shown that social marketing has made successes in various settings, these successes speaks much of its potential in addressing health behaviours and disease prevention. The technique has been used extensively in health programmes, especially for contraceptives and oral rehydration therapy (ORT) and used more frequently in the United States of America for such diverse issues as drug abuse, heart disease and organ donation (Weinreich, 2010).

Social marketing has been used to influence breastfeeding, hand washing, healthy eating, cervical screening, environmental impact, smoking cessation and physical activity (National Social Marketing Centre, 2006). Published evaluations in the sexual field suggest it has increased STI screening to heterosexual adolescents and condom use among adolescents (Bourne, 2011).

Gibson, Zhang, Cassady, Papppas, Mitchell and Kegeles (2010), also showed the role of social marketing in stalling HIV/AIDS in a research they conducted which revealed that exposure to posters and the newsletter was associated with decreased injection risk among injecting drug users. Noar and Kennedy,(2009) also the buttress the findings with evidence from several quasi-experimental designs that media campaigns can reduce rates of unprotected sex and increase HIV testing behaviours, although effects are typically short term.

While such surveys represent important contribution to the literature on the effectiveness of social marketing programmes especially on creating awareness and making condoms available in many of the world's developing countries, encouraging their use is very vital in the fight against HIV/AIDS. Social marketing programmes can do well in motivating individual behaviour change, but that is difficult to sustain unless the environment they are in supports such programmes.

In absence of a vaccine or an effective chemotherapeutic agent, the only weapon available for combating this dreadful infection is prevention through, health education and subsequent positive behaviour change (Tibdewel and Wadhva, 2007). Appropriate knowledge is a prerequisite for promoting prevention of HIV/AIDS. Lack of knowledge makes people vulnerable to HIV/AIDS infection. Comprehensive knowledge on HIV means knowing that consistent use of condoms during sexual intercourse and having just one HIVnegative faithful partner can reduce the chances of getting the AIDS virus.

According to Odu and Akanle (2008); Magnus and Gbekeji (2009) there is a relatively high level of awareness among people on the existence of the disease accompanied by a moderately high level of knowledge about HIV/AIDS route of transmission and the preventive measures of HIV/AIDS. A significant number of studies have shown that there is a moderately high level of awareness and knowledge on mode of transmission and the preventive measures of HIV/AIDS but, the virus is still spreading. The disparity between knowledge and behaviour may be responsible for the continuing spread of epidemic. The finding of Odu and Akanle (2008) revealed that a high percentage of awareness was available among people. However, among those who were aware of the consequences of HIV infection, no serious preventive efforts were taken towards avoiding the infection. This is so because most people felt that they can never contact HIV/AIDS. Garbati, Abba, Kabrang, and Yusuph(2011), identified that in a recent knowledge, attitude and practice (KAP) pilot survey among both new and old students of the University of Maiduguri revealed a generally informed population on HIV/AIDS education. This, however, did not translate to an improved acceptance of HCT services. From the pilot survey, about $4.7 \%$ of a cross-section of the student population from the institution tested positive to the virus.

Culture is that complex whole which includes knowledge, belief, art, morals, custom and habits acquired by man as a member of society. Culture is created by man and transmitted from one generation to another. The way people behave is largely influenced by the culture in which they had grown. Abiona (2008) states that traditional culture is a way of life or attitude developed through cultural practices or orientation, which have effects in determining patterns of behaviour within the community or towards certain programmes.Health issues are also affected by culture since culture influences day-to-day decisions, whereas some cultural values are desirable and beneficial to AIDS prevention and control, some are detrimental and further compound the situation. Traditional practices are important in maintaining cultural identity, but, some have harmful aspects.

Personality factors, concern about self-image, cultural norms, and inability to negotiate safe-sex limit people to transform their knowledge into perception. This can be seen from the findings of a study conducted by 
Adedimeji, Omololu and Odutola (2007), in which the level of risk behaviour was observed against a background of high risk perception, suggesting that young urban slum dwellers were aware of the risk associated with unprotected sexual activity but were constrained in adopting preventive measures. A possible reason for the observed relationship between perception of people and their sexual behaviour may be that there are a number of barriers to behaviour change such as belief, a range of traditional practices and socio-cultural norms, belief in a cure for AIDS and unreliable sources of information on sexuality (Odu and Akanle, 2008).

According to Momoh, Moses and Ugomoh (2007), socio cultural norms often discourage people from using preventive measures in the era of HIV/AIDS, even when they risk contracting the virus. Norms encourage men to take sexual risk; they are expected to be sexually knowledgeable and experienced, to be virile and healthy and may express sexual prowess to prove their manliness through casual and multiple partners, infidelity and dominance in sexual relation, this daunts men from asking questions or seeking STI/HIV/AIDS services.

On the other hand, girls and women are often raised to be submissive and unaware of sexual matters until marriage. They often fear reprisals from their partners and others, or being identified as promiscuous, immodest or unfaithful; if they raise issues related to sexuality and health including STI/HIV prevention. Norms discourage women from questioning their partners' sexual activities. Most cultures prevent women from using preventive measures. Asking a husband to use preventive measures requires that she plays a more assertive role than is the norm in most cultures (UNAIDS, 2006).

Other cultural and traditional beliefs surrounding sex and sexuality that exposes people to greater risk of HIV infection includes sexual rituals, motherhood sexual abstinence, certain communities belief recommend husbands to avoid sex with wives during pregnancy and breastfeeding to avoid baby's ailment. Meanwhile men seek other women outside. This exposes them to risk taking behaviour.Widow cleansing(Obiona, 2008), wife inheritance(UNAIDS, 2006), Wife snatching Mahmud (2010), Sexual violence(UNAIDS, 2002),Virgin myths, Resistance to condom usage, (Loosli 2004); (Amuyunzu-Nyamongo et al. 1999), Multiple sexual partners, Dry sexand Traditional surgeries(Obiona, 2008) are allexamples of cultural practices which can be devices that are likely predictors of exposure of HIV infection. Behavioural change is therefore an important means of HIV/AIDS mitigation measures.

\section{Methodology}

This study is a survey research; both primary secondary sources of data were utilised. Primary data were obtained through questionnaire and oral interview. The secondary data were collected from existing sources in books, journals, and government reports. The data were subjected to statistical analysis of Descriptive statistics and simple linear regression analysis using statistical package for social sciences (SPSS) version 16. The study considered people between the ages of sixteen (16) to sixty five (65) living within the metropolis. A sample size of 300 respondents was drawn using stratified and convenience sampling techniques.

Data Presentation

\section{Results}

\section{Awareness on HIV/AIDS}

Table 1: Frequency distribution of respondents' knowledge on transmission and prevention of HIV/AIDS

Source: Field Survey, 2011

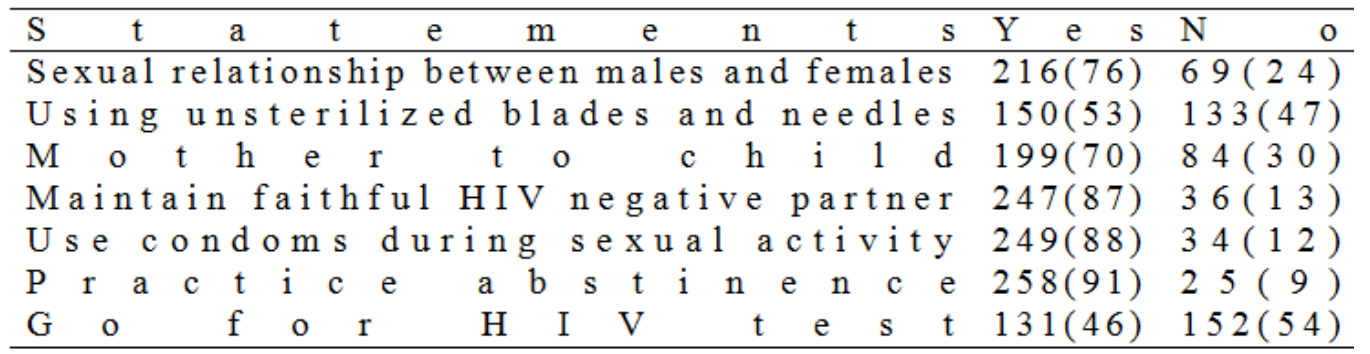

The analysis on table 1 shows that $76 \%, 53 \%, 70 \%, 87 \%, 88 \%$, and $91 \%$ of the respondents respectively have a high level of knowledge on HIV/AIDS. This reveals that the respondents are aware of HIV/AIDS, its modes of transmission and prevention.

\section{Responde Protevtive Behaviour}

The studyreveals that $70 \%$ of the respondents have not adopted any preventive measure while only $30 \%$ are protecting themselves. This clearly shows that the respondents are taking high risk by exposing themselves to infection through their risky behaviours. 
Influence of Compatibility with culture

Table2: Frequency distribution of influence of compatibility with culture on adoption of prevention

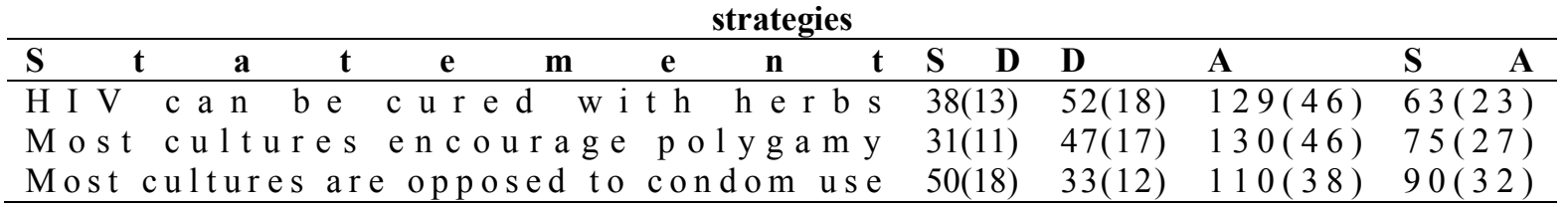

Source: Field Survey, 2011

The analysis on table 3reveals that $46 \%$ of the respondents agree believe the disease is curable using herbs while $27 \%$ strongly agree to it, $17 \%$ and $11 \%$ of the respondents disagree and strongly disagree with the statement. This is propagated by traditional healers. On the issue of polygamy, $63 \%$ of the respondents agree that most cultures encourage polygamy. Analysis on table 4.8 further reveals that, $70 \%$ of the respondents agree with the statement that most cultures are opposed to the use of condoms.

Table 3: components of culture that influences preventive health behaviour

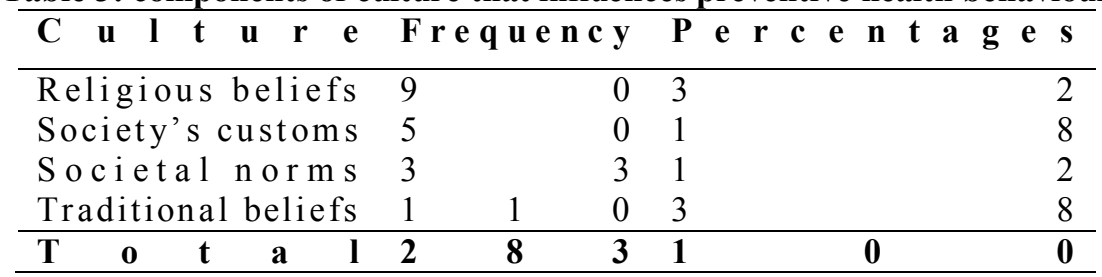

Source: Field survey, 2011.

Table 3 reveals that $38 \%$ of the respondents feel traditional beliefs influence preventive health behaviour while religious beliefs accounts for $32 \%$ of the respondents. Society's customs and societal norms are $18 \%$ and $12 \%$ respectively.

Table 4:Summary of linear regression estimates between compatibility and adoption of preventive strategies

\begin{tabular}{|c|c|c|c|c|c|c|c|c|}
\hline Variable & Constant & Coefficient & Standard Error & Beta Coefficient & $\mathrm{T}$ & r 2 & Adj. r2 & Sig. \\
\hline Compatibility & 12.928 & 2.35 & . 2661 & . 4995 & 9.04 & .25 & 2 & .000 \\
\hline
\end{tabular}

Source: Tables 2 and 3

A simple linear regression analysis was used to test the hypothesis. The result of the regression analysis indicate, $\mathrm{r}=.495, \mathrm{~F}(1,282)=9.037, \mathrm{P}<.01$. Based on the result, the null hypothesis is rejected. There is a relationship between compatibility and adoption of preventive strategies. Compatibility significantly affects safe behaviour change.

\section{Level of awareness/ knowledge on HIV/AIDS}

\section{Discussion of Findings}

The respondents' answers on modes of transmission and preventive measures of HIV scored high which show a high level knowledge on awareness. Over $80 \%$ of the respondents have comprehensive knowledge of HIV/AIDS; which is the consistent use of condoms and maintaining a faithful HIV negative sexual partner. It is discouraging however; that slightly more than $50 \%$ of the respondents know that to have a voluntary HIV test is a preventive measure. To know ones status is very important in the war against the virus. From this study, the level of awareness and knowledge on HIV/AIDS is high. This is in line with findings of Amuyunzu-Nyamongo et all, 1999); Adedimeji, et al (2007); Odu and Akanle (2008); Magnus and Gbekeji (2009).

\section{Respondents' protective behaviours}

The study examined the protective behaviours of the respondents and it revealed that most of the respondents were exhibiting high risk behaviours as 70\% had not adopted any form of protection. Abstinence was the most popular form of protection for only $14 \%$ of the respondents; this clearly shows that the majority of the respondents are sexually active. It is very discouraging that only $7 \%$ were using condoms as a means of protection. This is in line with findings of Adedimeji, et al. (2007); Odu and Akanle (2008); Magnus and Gbekeji (2009); and Asakun-Olarinmoye (2009) where most of the respondents were exhibiting high risk behaviours despite their awareness. 


\section{Influence of compatibility with culture on adoption of HIV/AIDS prevention strategies in Maiduguri metropolis}

About two-thirds of the respondents are of the view that some cultural and traditional practices do influence behaviour change as seen from their responses which can aid the spread of the virus. Majority believe in the efficacy of traditional medicines which they believe can cure the disease; this encourages them to take sexual risks as it exposes them to the virus. Also, majority of the respondents $(63 \%)$ are of the opinion that culture is not opposed to polygamy as it encourages them to have many sexual partners. Again a very high number of the respondents $(70 \%)$ say most cultures frown at the use of condoms within marriages.

Findings of earlier researches by Loosli (2004); Ambasa-Shisanya (2006); Abiona (2006); Momoh, Moses and Ugiomah (2007); Danesi (2008); Obiona (2008) and Mahmud (2010), some socio-cultural norms discourage people from using preventive measures in the era of HIV $\backslash$ AIDS, even when they risk contracting the virus. Female are expected to be silent over sexual issues while males can have multiple sexual partners to prove their manliness. Condoms should not even be considered because married people are expected to procreate, also some traditional practices exposes people to high risk behaviours. The study sought to ascertain the components of culture that influences health preventive behaviour of people. Traditional and religious beliefs were highest influencing $70 \%$ of the respondents. This shows that prevention strategiesthat are not harmonious with such beliefs in any society will be difficult to accept by the people.

This study examined the relationship between compatibility and adoption of HIV/AIDS prevention strategies and it revealed that there is a relationship between compatibility and adoption of HIV/AIDS prevention strategies. A simple linear regression was used to test the hypothesis which shows compatibility has a significant influence on adoption of HIV/AIDS preventive strategies Maiduguri metropolis

\section{Conclusion}

After decades of fighting the dreaded HIV/AIDS in Nigeria, the country is yet to achieve much, especially in the area of prevention; which is attitudinal and behavioural change. Considering the fact that very little is known on the cure for the disease, the world needs to put more emphasis on prevention. The Nigerian Government, donor agencies, and other bodies have done a lot by using communication in creating awareness for HIV/AIDS but have not achieved much success in behaviour change.

Awareness for HIV has been raised but this awareness and knowledge on modes of transmission and prevention strategies are not predictors of safe behaviour change. Factors within individuals, their environment and the characteristics of the innovation are responsible for non-adoption of HIV/AIDS prevention strategies. To bridge the gap between awareness and action, there is a need to move beyond awareness and to achieve sustained behaviour change.

\section{Recommendations}

1. "Cultural" social marketing should be used where community leaders and community elders are recognised and persuaded to promote cultural practices which can prevent HIV infection rather than those practices that are barriers to its prevention; these people are role models as they are opinion leaders whom people look up to.

2. "Religious" social marketing should be used where religious groups/leaders of all faiths are targeted and made to be integral part of the campaigns against HIV as these leaders can enhance the credibility of messages and promote their acceptance.

3. HIV test should be made compulsory before marriage in all communities. This can be achieved by enlisting opinion leaders (religious leaders and community leaders). This compulsory test should have a constitutional backing where such marriages conducted without the test will not be recognised by the community.

\section{References}

[1]. Abiona A. I. (2006). The Influence of Primordial Culture and HIV/AIDS Awareness Programme on Stigmatization of HIV/AIDS Patients in Oyo State, Nigeria.Premises for Community Education Intervention,International Journal ofAfrican and African American Studies Vol. No. 1 .

[2]. Adedimeji, A.A, Omololu, F. O. \& Odutolu, O. (2007). HIV Risk Perception and Constraints to Protective Behaviours among young slum Dwellers in Ibadan,Nigeria. Journal of Health, Population and Nutritional. Vol.25, No 2.

[3]. Agbonifoh, B., Ogwo, E., Nnolim, D., \& Nkamnebe, A. (2007).Marketing in Nigeria: concepts, principles anddecisions: Afritowers Books. 1 Second Edition.

[4]. Ambasa-shisanya, C. R. (2006). Cultural Determinants of Adoption of HIV/AIDS Prevention Measures and strategies among Girls and Women in Western Kenya.OSSREA Publications.

[5]. Amuyunzu- Nyamongo, M., Tendo-Wambua, L., Babishangire, B., Nyangero, J., Yitbarck, N Matasha, M \& Omurwa, T (1999). Barriers to Behaviour Change as a Response to STD including HIV/AIDS: the East Africa Experience.African Medical ResearchFoundation.

[6]. Bourne, A. (2011), Social Marketing and HIV Prevention.Making it Count Briefing Sheet 6.Sigma Research at LSHTM. 
[7]. Cugelman, B. (2012). Why Digital Behaviour Change Interventions will transform Public Health. Ontorio health promotion EBulletin, volume 754 .

[8]. Fox, K.F.A. \&Kotler, P. (1980), The Marketing of Social Causes: The First 10Years. Journal of Marketing. Volume 44.Number 4.

[9]. Gibson, D. R, Zhang, G, Cassady, D, Pappas, L, Mitchell, J \&Kegeles, S.M. (2010). Effectiveness of HIV Prevention Social Marketing with Injecting Drug Users, Am Public Health. V. 100(10).

[10]. Garbati, M.A, Abba, A .A, Kabrang, D.N and Yusuph, H. (2011). HIV/AIDS in Northeastern Nigeria: A review.Journal of Infectious Diseases and Immunity Vol. 3(10), pp. 176-182, 15 October, 2011 Available online at http://www.academicjournals.org/JIDI ISSN 2141-2375.

[11]. Kotler, P \& Lee, N.R. (2008), Social Marketing: Influencing Behaviour for Good, Social Marketing Services Inc.

[12]. Kotler, P. \& Zaltman, G. (1971), in Fox, K.F.A \& Kotler, P. (1980), The Marketing of Social Causes: The First 10Years. Journal of Marketing. Vol. 44. No 4

[13]. Hussain, S. \& Shaikh, B. T. (2005), Stalling HIV through Social Marketing: prospects in Pakistan.J Pak Med Assoc, vol. 55 , No. 7.

[14]. Loosli, B. C (2004). Transitional practices and HIV prevention in sub-Saharan Africa.Swiss Red Cross Report, Geneva.

[15]. Magnus, O.O. \& Gbekeji, J.O. (2009). Analysis of Spatial Awareness of HIV/AIDS Among Student of Tertiary Institutions in Edo State, Nigeria, Etho-Med 3(2).

[16]. Mahmud, M.U. (2010). A Study of the use of Radio in HIV/AIDS Mitigation in Four Local Government Areas of Kaduna State.MAJASS.Vol.8 No.2.

[17]. Momoh, S.O. Moses, A.I, \& Ugiomoh, M.M. (Sept 2007). Women and HIV/AIDS Epidemic: The Issue of College Age Girl's Awareness in Nigeria.College Student Journal.

[18]. National Social Marketing Centre. (2006) It's our health! Realising the potential of effective social marketing. London, National Consumer Council.

[19]. Noar, S.M. Kennedy, M.G. (2009). HIV/AIDS Prevention Messages.Virtual Mentor, vol. 11, number 12: 980 -987.

[20]. Obiona E.E. (2008). Exploring the culture context of HIV/AIDS pandemic specific in a Nigerian Community: Implication for culture specific prevention Programmes. Anthropologist, 10 (4).

[21]. Odu, B. K. \& Akanle, F.F. (2008).Knowledge of HIV/AIDS and sexual Behavior among the Youths in South West Nigeria, Humanity and Social Science Journal 3(1), Idosi Publications.

[22]. Oguntola, S. (2010). Why Condoms Reduce Sexual Pleasure, Accessed on 11/12/2010.

[23]. Smith, W.A. (UD). Social Marketing: Two Approaches to HIV/AIDS Prevention in HIV/AIDS Prevention and Care in Resource Constrained Settings, Chapter 12, page $281-304$.

[24]. Tibdewel, S.S. \& Wadhva, S. K. (2007).http://www.health.am/aids/mire/hiv-aids-Awareness-among-hospital-employees/source: Armenian Medical Network Retrieved on 11/12/2010.

[25]. Weinreich, N.D. (2010).What is Social Marketing? Social Marketing Institute. http:/www.social marketing.org/what is.html

[26]. UNAIDS, WHO, AIDS Epidemic Update: December 2, 2002. Geneva Joint United Nations Programme on HIV/AIDS

[27]. United Nations Action on Aids Programme (2006). Reports on Global HIV/AIDS Epidemic, Genera. Switzerland.

[28]. WHO/UNAIDS, (2006). AIDS Epidemic Update: Special report on HIV/AIDS. WHO/UNAIDS. Accessed from www.unaids.org.on 11/11/2010 